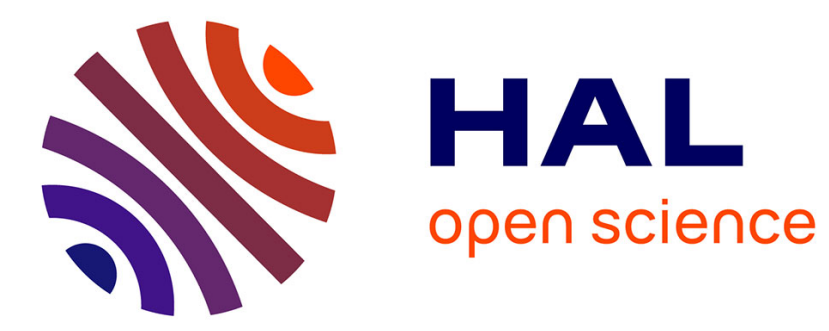

\title{
Mathematics. Systematical concepts
}

Paola Cantu

\section{To cite this version:}

Paola Cantu. Mathematics. Systematical concepts. Robert Theis; Alexander Aichele. Handbuch Christian Wolff, Springer VS, pp.357-379, 2018, 978-3-658-14736-5. 10.1007/978-3-658-14737-2_17 . hal-01701635

\section{HAL Id: hal-01701635 \\ https://hal.science/hal-01701635}

Submitted on 15 Feb 2022

HAL is a multi-disciplinary open access archive for the deposit and dissemination of scientific research documents, whether they are published or not. The documents may come from teaching and research institutions in France or abroad, or from public or private research centers.
L'archive ouverte pluridisciplinaire HAL, est destinée au dépôt et à la diffusion de documents scientifiques de niveau recherche, publiés ou non, émanant des établissements d'enseignement et de recherche français ou étrangers, des laboratoires publics ou privés. 
10.2. Mathematics. Systematical Concepts

Paola Cantù

\section{Keywords}

Wolff, mathematical method, number, quantity, similarity, probability

\section{Abstract}

The paper investigates the notions of number, extensive quantity, algebraic quantity, similarity, and probability as introduced in Wolff's mathematical writings, and evaluates the coherence of these definitions with Wolff's presentation of the mathematical method. Wolff's original epistemology is based on the belief that the discussion on the foundation of mathematics and on the history of mathematical ideas is essential not only to pure mathematics but also to its application and teaching. Mathematics is integrated into a larger body of knowledge and subordinated to philosophy, which explains the impurity of definitions and proofs and why certain notions, such as that of similarity and probability, cannot be understood without reference to ontology and logic. Wolff's investigation of probable propositions allowed for a unique demonstrative methodology applied to philosophical mathematical and historical knowledge, thus explaining probable reasoning as an insufficient knowledge of the requisites for the truth of the premises. This explains the importance assigned to the right order of concepts and the inferential role of definitions. The paper shows the internal coherence between Wolff's choice of mathematical definitions and his overall epistemology, and underlines the heritage of Descartes, of Barrow's edition of Euclid's Elements and of Aristotle's notion of contiguity rather than the influence exerted by Leibniz's mathematics or by Newton's fluentist conception of geometrical quantities. 


\section{Introduction}

Both in philosophy and in mathematics Wolff has been often considered as a mere epiphenomenon of other authors (Leibniz, Euclid), and at most appreciated for his didactical influence. The construction of the so-called Leibnizio-Wolffian tradition has played this role in the history of philosophy. In the history of mathematics, Wolff was mainly mentioned for his influential textbooks, which practically substituted Euclid's Elements in the university curricula. His mathematical contributions, on the contrary, have been mostly criticized, because of his insistence on geometrical representation, on the non-existence of negative quantities, and on the idea that infinitesimals cannot be taken to be numbers (see $\S 2.4$ ). ${ }^{1}$

Whereas the literature on Wolff's philosophy is now quite rich, the same cannot be said for the analysis of Wolff's mathematical notions, which are still evaluated mainly in comparison with others' ideas-especially Euclid's ${ }^{2}$ or Leibniz's, ${ }^{3}$ or appreciated for

${ }^{1}$ Interesting exceptions are Shabel and Schubring, who analyze in detail Wolff's mathematical practice and Wolff's foundational stance on algebra, geometry, and analysis. Shabel traces the origin of Wolff's concept of number in traditional geometric notions, underlying the connection with a mathematical tradition that was strongly influenced by Euclid, and includes Descartes, Viète, Williamson, Barrow and Lamy. Schubring discusses at length the connection between proportion theory and Wolff's reasons for refuting the idea that zero is a number, as well as earlier and later supporters of similar arguments (Arnauld, Leibniz, Duhamel, Martin). See Lisa Shabel, Mathematics in Kant's Critical Philosophy. Reflections on Mathematical Practice, New York and London, 2002; see also Gert Schubring, Conflicts Between Generalization, Rigor, and Intuition. Number Concepts Underlying the Development of Analysis in 17th-19th Century, New York, NY, 2005.

2 See Shabel, Mathematics in Kant's Critical Philosophy. Reflections on Mathematical Practice, op. cit.; see also Henk J.M. Bos, Lectures in the History of Mathematics, London, Providence, 1993, pp. 141-152.

${ }^{3}$ See Shabel, Mathematics in Kant's Critical Philosophy. Reflections on Mathematical Practice, op. cit.; see also Katherine Dunlop, Mathematical method and Newtonian science in the philosophy of Christian Wolff, in: Studies in History and Philosophy of Science Part A 44/3 (2013), 
their historical and pedagogical impact. ${ }^{4}$ For example, Wolff has been considered as an opponent of negative numbers, ${ }^{5}$ and opposed to Kant. ${ }^{6}$ Exception made for Kästner and Lambert, who associated a sharp criticism of specific aspects of Wolff's mathematics with a general praise of his difficult enterprise, mathematicians have been mainly critical towards Woff (e.g. Gauss and Schumacher, Euler, .... ${ }^{7}$

This article will investigate Wolff's mathematical definitions from a point of view that is rather internal to his epistemology, especially in the light of the mathematical method presented in the mathematical writings. The aim will be to evaluate the coherence and epistemic value of , Wolff's elucidation and definition of mathematical technical terms. Much has been said in the literature about Wolff's mathematical method, but the focus has often been on the application of this method to Wolff's philosophy, or its intrinsic relation to logic. ${ }^{8}$ Consequently, the mathematical method has often been pre-

Cf. Charles A. Corr, Christian Wolff and Leibniz, in: Journal of the History of Ideas 36(2) (1975), pp. 241-262.

${ }^{4}$ See Joseph W. Dauben and Cristoph J. Scriba, Writing the History of Mathematics. Its Historical Development, Basel, 2002.

${ }^{5}$ See Johann Michael Hube, Versuch einer Analytischen Abhandlung von den Kegelschnitten, Göttingen, 1759, p. xxxi, cited in Schubring, Conflicts Between Generalization, Rigor, and Intuition, op. cit., p. 135, fn.77.

6 See Jennifer McRobert, Kant on negative quantities, real opposition and inertia, Paper Presented at the 2004 Meeting of the Western Canadian Philosophical Association in Victoria B.C., Canada, 2004.

${ }^{7}$ See Christian Friedrich Gauss, Briefwechsel zwischen C.F. Gauss und H.C. Schumacher, ed. by C.A.F. Peters, Altona, vol. 4, 1862, pp. 332-342; see also Calinger, R. S. (2015). Leonhard Euler: Mathematical Genius in the Enlightenment. Princeton, NJ, 2015, pp. 146 ss.; see Schubring, Conflicts Between Generalization, Rigor, and Intuition, op. cit., p. 134 and p. 135, fn, 77.

${ }^{8}$ See Herman J. d. Vleeschauwer, (1931). La genèse de la méthode mathématique de Wolff, in: Revue belge de philologie et d'histoire 11 (1931), pp. 651-677; see Giorgio Tonelli, Der Streit über die mathematische Methode in der Philosophie in der ersten Hälfte des 18. Jahrhunderts und die Entstehung von Kants Schrift über die "Deutlichkeit", in: Archiv für Philosophie 9 (1959), pp. 51-84; see 
sented as it is introduced in Wolff's philosophical-especially logical or metaphysicalwritings. The starting point here will be the method as it is presented in the mathematical writings, in order to verify its application in Wolff's mathematical textbooks. We will consider here only pure mathematics, but a second step of the investigation should include applied mathematics too, given Wolff's firm belief that applications belong to mathematics, and especially that the practical use of a theory should be explained together with the theory itself. ${ }^{9}$ The analysis is focused on the first edition of Wolff's Mathematical Dictionary, ${ }^{10}$ on the German and Latin editions of the Elements of All Mathematical Sciences, on their German and Latin summaries, and on the Mathematico-Philosophical Essays and Dissertations (1740). ${ }^{11}$

Tore Frängsmyr, Christian Wolff's mathematical method and its impact on the Eighteenth century, in: Journal of the History of Ideas 36/4 (1975), pp. 653-668; see Guido Zingari, Die Philosophie von Leibniz und die "deutsche Logik" von Christian Wolff, in: Studia Leibnitiana 12/2 (1980), pp. 265278; see Katerine Dunlop, Mathematical method and Newtonian science in the philosophy of Christian Wolff, in: Studies in History and Philosophy of Science Part A 44/3 (2013), pp. 457-469; see Paola Basso, Il secolo geometrico. La questione del metodo matematico in filosofia da Spinoza a Kant. Firenze, 2004; see Volker Peckhaus, Logik, Mathesis universalis und allgemeine Wissenschaft. Leibniz und die Wiederentdeckung der formalen Logik im 19. Jahrhundert. Berlin, 1997; see Ferdinando L. Marcolungo, Wolff e il problema del metodo, in: Nuovi studi sul pensiero di Christian Wolff, ed. by Sonia Carboncini and Luigi Cataldi Madonna, Hildesheim, Zürich and New York, 1992, pp. 11-37.

9 See Henk J.M. Bos, Lectures in the History of Mathematics. Providence, RI and London, 1993. p. 146.

10 Wolff never acknowledged further editions of the dictionary. See Christian Wolff, Elementa Matheseos V, chap. 1, p. 10 (GWII 33). See also Moritz Cantor, Vorlesungen über die Geschichte der Mathematik, Leipzig, vol. 3, 1898, p. 478.

11 See in particular the following writings: Mathematisches Lexicon (1717) (GW I 11), Auszug aus den Anfangs-Gründen aller mathematischen Wissenschaften (1732) (GW I 25), AnfangsGründe aller mathematischen Wissenschaften (1737) (GW I 12-15), Elementa Matheseos I-V (174046) (GW II 29-33), Christiani Wolfii Meletemata Mathematico-Philosophica Quibus Accedunt Dissertationes (1740) (GW II 35), Kurtzer Unterricht von den vornehmsten mathematischen Schriften (GW I 15.2). 
Among the most important mathematical concepts defined by Wolff, one should examine the notions of number, extensive quantity and algebraic quantity-occurring in the definition of mathematics itself-, but also the concept of probability, ${ }^{12}$ the notions of infinitesimals and continuum, ${ }^{13}$ and the concept of similarity, which is related to the concepts of quantity and quality. ${ }^{14}$

\section{Mathematics consists of arithmetic, algebra and geometry}

The concepts of arithmetical number, algebraic quantity, and geometrical magnitude are the subjects of what Wolff identifies as the three main disciplines of mathematics: arithmetic, geometry, and algebra. The analysis of Wolff's definition of these notions is useful to test his mathematical method, which rests exactly on the analysis and comparison of definitions. As Cantor remarked, the mathematical dictionary is a collection of definitions or clarifications of mathematical technical terms, rather than an introductory survey of mathematics. ${ }^{15}$ The survey of contemporary mathematics is not extensive neither in the Latin nor in the German version of the Elements of Mathematics either, and many shortages and gaps have been remarked. Besides criticism of shortages and gaps in the treatment of mathematical topics, mathematicians criticized Wolff's choice of definitions: e.g. Schumacher and Gauss commented on the errors

12 See Luigi Cataldi Madonna, Wolff, Bolzano e la probabilità, in: Nuovi studi sul pensiero di Christian Wolff, ed. by S. Carboncini and L. Cataldi Madonna, Hildesheim and New York, NY, 1992, pp. 107-130. See also Martin Schönfeld, Wolff, Christian (1679-1754), in: Encyclopedia of Philosophy, ed. by D. M. Borchert, Detroit, vol. 9, 2006, pp. 822-832. See Luigi Cataldi Madonna, Wahrscheinlichkeit und wahrscheinliches Wissen in der Philosophie von Christian Wolff. Studia Leibnitiana XIX/1 (1987), pp. 2-40.

13 See Gert Schubring, Conflicts Between Generalization, Rigor, and Intuition. op. cit.

14 See Daniel Sutherland, Philosophy, Geometry, and Logic in Leibniz, Wolff, and the Early Kant, in: Discourse on a New Method: Reinvigorating the Marriage of History and Philosophy of Science, ed. by M. Friedman, M. Domski, and M. Dickson, Chicago, 2010, pp. 155-192.

15 Moritz Cantor, Vorlesungen über die Geschichte der Mathematik, op. cit., p. 477. 
contained in the definition of barycenter. ${ }^{16}$ This proves not only the difficulty but also the fruitfulness of Wolff's enterprise, which had at least the merit of highlighting the problematicity of several definitions actually used in the mathematical practice or in the teaching practice, thereby calling for emendations. But the modernity of Wolff's perspective, lies mainly in his belief that the discussion on the foundation of mathematics and on the history of mathematical ideas is not only intrinsic to the development of pure mathematics, but is also essential to the applications of mathematics and to the educational enterprise. Not only did he create a new literary genre (see e.g. Bolzano's text "On the mathematical method"), but based his textbooks on extensive surveys of mathematical literature, long before Kästner. ${ }^{17}$

\subsection{Mathematics as the science of quantities}

Mathematics is, according to Wolff's definition in the Mathematical Dictionary, a science that measures all that can be measured, a "science of quantities" [scientia quantitatum, Grössenlehre], i.e. a science of all things that can be enlarged or reduced; pure mathematics embraces only three disciplines: geometry, arithmetic and algebra. ${ }^{18}$ In the Latin version of the Elements of mathematics Wolff distinguishes between arithmetic, geometry, trigonometry, finite analysis (algebra), and infinite analysis (dif-

16 See Christian Friedrich Gauss, Briefwechsel zwischen C.F. Gauss und H.C. Schumacher, ed. by C.A.F. Peters, Altona, vol. 4, 1862, pp. 332-342.

17 I do not share here Dauben and Scriba's diminishing remark that Wolff's achievements in the fifth volume of the Anfangsgründe and in the fifth volume of the Elementa Matheseos, were "no more than a dry annotated guide to the literature", or Struijk's comment on Kästner's Geschichte der Mathematik as "an artless compilation of titles and descriptions of ancient books without an attempt at a readable narrative". See Dauben, and Scriba, Writing the History of Mathematics. Its Historical Development, op. cit., pp. 111-113.

18 See Mathematisches Lexicon, pp. 864-66 (GW I 11). But in the entry on mathesis pura, Wolff also mentions trigonometry as a distinct discipline. Ibid., p. 868 (GW I 11). 
ferential and integral calculus). ${ }^{19}$ But to better understand what mathematics is, let's look at what it is not.

Mathematics is not a universal mathesis, which means that mathematics is not a calculus, because Wolff distinguishes four different conceptions of mathesis universalis, which have in common exactly the fact that they are kinds of calculi: 1) Rasmus Berthelsen's art of symbolical calculus, 2) John Wallis' calculus with cyphers and letters, 3) the investigation of general properties of quantities by means of the symbolical calculus, and 4) Leibniz's science of the measurement of all things. ${ }^{20}$ Wolff's distinction is acute, because he clearly distinguishes four tendencies in mathematics that have sometimes been misunderstood: 1) the literal calculus, 2) the unification of arithmetical and algebraic calculus (Wallis), 3) the study of general properties of magnitudes (Viète, Descartes, Newton), and 4) the investigation of other things beyond quantities (Leibniz). Yet, Wolff does not really do justice to Leibniz's project, because even if he rightly asserts that it concerns all things, he also insists on the notion of measurement, whereas Leibniz claims that the mathesis universalis does not concern only the relationship of equality, and thus size and quantities, but also other types of relationships between things, and therefore also quality. ${ }^{21}$

19 See Elementa Matheseos I, § 132, p. 341 (GW II 29). Note that in the Mathematical Dictionary, the differential calculus included differential, exponential and integral calculus [Calculus differentio-differentialis, exponentialis, integralis seu sommatorius]. See Mathematisches Lexicon, pp. 283-291 (GW I 11). Analysis is a part of algebra because differentiation and integration were conceived as arts of calculi, or, as Shabel has claimed, because both analysis and algebra are, in a sense, arts of calculi. See Shabel, Mathematics in Kant's Critical Philosophy. Reflections on Mathematical Practice, op. cit.

20 See Mathematisches Lexicon, p. 869 (GW I 11).

21 See Gottfried W. Leibniz, Mathesis universalis, in: Leibnizens mathematische Schriften, ed. by C.I. Gerhardt, vol. 7, Halle, 1863, pp. 49-76. See also Vincenzo De Risi, Geometry and Monadology: Leibniz's Analysis Situs and Philosophy of Space, Basel, Boston and Berlin, 2007, p. 118. 
To resume, mathematics is the science of the measurement of certain kinds of things that Wolff generically calls quantities. To avoid the ambiguity of the term, let's turn to the analysis of the objects of the main mathematical disciplines: the number in arithmetic, extensive quantities in geometry, and quantity in algebra.

\subsection{Arithmetical numbers}

Wolff defines arithmetic (Arithmetica, Rechenkunst) as the science of number, which includes the infinitesimal calculus and the arithmetic of irrationals. ${ }^{22}$ Again, arithmetic is better understood by verifying what it is not: it is distinguished from the algebraic or literal calculus [arithmetica speciosa sive litteralis, Buchstabenrechenkunst], and from algebra, which Wolff conceives as the theory of equations (see further $\S 2.4$ ). ${ }^{23}$ Yet, Wolff's analysis undergoes some changes in time, because in the later Latin versions of the Elements of mathematics, algebra is merged with finite analysis, and the latter is part of arithmetic. ${ }^{24}$

If arithmetic is the science of number, and includes analysis, the definition of number [numerus, eine Zahl] should be as general as possible, in order to include not only integers, but also rational and irrational numbers, and even 1 , which is not a number according to the Euclidean definition of number as a multitude of units. ${ }^{25}$ On the contrary, the definition should not be as general as to include zero, which is, according to Wolff, a sign, and not a concept. This depends on the metaphysical implications of Wolff's understanding of a concept as a representation of a thing that the subject

\footnotetext{
22 See Mathematisches Lexicon, pp. 169, 176, 179 (GW I 11).

23 Ibid., pp. 280, 292, 178 (GW I 11).

24 See Elementa Matheseos I, §132, p. 341 (GW II 29).

25 See Mathematisches Lexicon, p. 945 (GW I 11).
} 
should acknowledge. Zero [Cyphra, eine Nulle] is not a concept, because it does not represent anything; it is rather a cipher that is used in decimal notation. ${ }^{26}$

Wolff defines a number as "what stands in proportion to 1 as a straight line stands in a proportion to another straight line". ${ }^{27}$ For example, an integer [Numerus integer, ganze Zahl] is "a number that stands in proportion to 1 as the whole stays to a part"; a fraction [Fractio, Bruch] is "a number that stands in proportion to 1 as a part stays to the whole"; a rational number [Numerus rationalis, eine Rational-Zahl] is "a number that consists either of pure units or of equal parts of the units"; an irrational number [Numerus irrationalis, surdus, eine Irrational-Zahl] is "a number that has no rational proportion to $1^{\prime \prime} .^{28}$ So, arithmetic is the science of natural, fractional, rational and irrational numbers.

It should be noted that fractions are numbers of the form $1 / b$, whereas rationals have the form $a / b$, with $a$ and $b$ natural numbers. Even if this is certainly far away from the contemporary distinction between fractions and rational numbers (a distinction that has been introduced only at the beginning of the $20^{\text {th }}$ century, ${ }^{29}$ it is very interesting to remark that Wolff accurately distinguishes these two kinds of number, which are used in different ways in the applications: one thing is to divide a whole into parts (fraction), another thing is to measure how many times a quantity is measured by another quantity, thereby establishing the ratio of two quantities. Wolff's belief that the applica-

26 "The symbol 0 , denoting nothing [...] is needed to fill in the empty places, where no number stands. For example 1 means in the third place 'hundred': to understand that it stays in the third place, when there are no other numbers near to him, two zeros are placed there. So, 'hundred' is written 100". Ibid., p. 1485 (GW I 11).

27 Ibid., p. 944 (GW I 11).

28 Ibid., pp. 953, 647, 965, 953 (GW I 11).

${ }^{29}$ See Alessandro Padoa, Che cosa è una relazione?, in: Atti della Accademia Reale delle Scienze di Torino, 41 (1905-06), pp. 818-826. See also Alessandro Padoa, Frazioni, relazioni ed astrazioni, in: Periodico di Matematica, (3) 25/7 (1910), pp. 257-258. 
tions of mathematics belong to mathematics is here evident: the operation that gave origin to the specific kind of number is recalled in its definition. Only afterwards, a general definition is given that might include all the specific cases. As a result, one should not expect Wolff to produce pure definitions, i.e. definitions that include notions belonging to the same discipline, e.g. only arithmetical notions in arithmetic. Another reason is of course that mathematics is subordinated to philosophy. ${ }^{30}$ Wolff's definition of number is impure for two reasons: it presupposes the notion of straight line, and the notion of 1 . If 1 is conceived as the integer number 1 , then the definition is circular (at least in the case of number 1 itself). If 1 is conceived as the whole, then metaphysical, or more precisely ontological notions enter into the definition of number, which is then impure because philosophical considerations enter into an arithmetical definition.

The presence of non-arithmetical elements in Wolff's definition has been explained in the literature as an effect of his interpretation of Descartes' geometry, where an oper-

30 The notion of purity is usually applied to proofs, and goes back to a passage by Aristotle, where he claims that "you cannot prove anything by crossing from another kind-e.g. something geometrical by arithmetic. ... where the kinds are different, as with arithmetic and geometry, you cannot attach arithmetical demonstrations to what is incidental to magnitudes-unless magnitudes are numbers. ... Hence the kind must be the same, if a demonstration is to cross". See Aristotle, Posterior Analytics, 75a-75b, transl. by Jonathan Barnes, Oxford, 1994, p. 12. The notion of a pure definition is less common in the literature. Transposing Arana's notion of extraneousness from proof to definitions is one way to give a general definition of impure definition, i.e. definitions containing notions that are extraneous to the disciplinary field. See Andrew Arana, On formally measuring and eliminating extraneous notions in proofs, in: Philosophia Mathematica 17/2 (2009), pp. 189-207 and also Andrew Arana, Purity in arithmetic: Some formal and informal issues. In Formalism and Beyond. On the Nature of Mathematical Discourse, ed. by M. Detlefsen and G. Link, Boston, 2014, pp. 275314. Craig Walton used the notion of impure definition in a different sense, as he considered Ramus as one of the first who explicitly introduced impure definitions in mathematics, i.e. including notions that do not belong to pure mathematics but rather to its applications. See Craig Walton, Ramus and Socrates, in: Proceedings of the American Philosophical Society 114/2 (1970), p. 122. 
ation of addition and multiplication is defined on segments by means of certain geometrical constructions. ${ }^{31}$ Following Euclid, Wolff defines a ratio as "the relation of a thing to another homogeneous thing that determines the quantity [Grösse] of the former by means of the quantity of the latter, without need for a further measure [Maass]. For example, "taking the width of a window as measurement unit, then if the length of the window is the double of the width, the relation of the latter to the former is $1: 2$. On the contrary, if the length of the window is taken as measurement unit, then the relation of the height to the width is $2: 1 .^{\prime \prime 2}$ So, a ratio of two quantities expresses a measurement of the quantities, but is not a number. Number are introduced only by proportions, i.e. by "the similarity of two ratios". ${ }^{33}$

It has been remarked that Wolff's definition is similar to Newton's definition of number as the ratio of two quantities, but Newton is not explicitly mentioned in the 1714 edition, and one should note that Wolff defines number as the fourth proportional of a proportion and not explicitly as the ratio of two quantities. This difference is even more evident if one considers that Newton's definition is not as impure as Wolff's. The modern aspect of Wolff's notion, an aspect that he was probably unaware of, is that

31 See Shabel, Mathematics in Kant's Critical Philosophy. Reflections on Mathematical Practice, op. cit. Shabel's remarks on the geometrical origin of the notion are certainly confirmed by Wolff's own claim that his definition explains why "it is possible to multiply and divide lines by lines so that the product or respectively the quotient might be itself a line, as Descartes showed in Book 1 and 2 of Geometry", and is thus useful in the application of algebra to geometry. See Mathematisches Lexicon (GW I 11), pp. 944-5. Yet, it should be remarked that Wolff gives an epistemological justification too. Wolff's notion of number satisfies what is nowadays called an "application constraint", i.e. the fact that the notion already contains a hint to its possible application.

32 Ibid., p. 1169 (GW I 11). See also Elementa Matheseos I, § 126, p. 55 (GW II 29).

33 See Mathematisches Lexicon, p. 1105 (GW I 11). Here Wolff introduces only numerical examples, but he elsewhere considers generic quantities (letters or numbers). See Elementa Arithmeticae, part III, § 155 in Elementa Matheseos I, p. 60 (GW II 29). See Gert Schubring, Conflicts Between Generalization, Rigor, and Intuition, op. cit. 
measuring (constructing ratios of quantities) might take place both between numbers and between lines, but numbering arises only when one perceives the similarity between the two ratios by means of a proportion. In modern parlance, numbering occurs when one recognizes by means of a representation theorem that the structure of a given numerical system and the structure of the quantities to be measured are similar.

\subsection{Geometrical extensive quantities}

The definition of geometry and in particular of geometrical quantities is ambiguous. It changes in time, and expresses in the clearest way Wolff's tension between the attention to mathematical practice, the search for distinct and adequate definitions (see below), and the debt to Euclid's tradition. Wolff considers geometrical quantities sometimes from a rather applied perspective (e.g. in the Anfangsgründe and in the Mathematisches Lexicon), and sometimes from a pure mathematical point of view (as in the latter editions of the Elementa Matheseos). Besides, Wolff is partly fascinated by Barrow's edition of the Elements, and partly strongly unsatisfied with the order of the propositions in the Elements. The definition of arithmetic is based on the kind of objects it concerns (i.e. numbers) but can also be enriched by opposition to what arithmetic is not (mathesis universalis). Geometry on the contrary is defined only by reference to its objects. This makes it more difficult to understand what it actually is, especially because Wolff gives at least two rather divergent definitions.

In early works, geometry "is the science of space, which considers physical things according to their length, width, and height", whereas in later writings it is "the science of extensive things (Extensorum), inasmuch they are finite, i.e. lines, surfaces and solids".$^{34}$ In the Mathematical Dictionary Wolff considered lines and surfaces as abstractions of solids, claiming that lines are quantities, but cannot actually be separated in

${ }^{34}$ See Mathematisches Lexicon, p. 665 (GW I 11); see also Elementa Matheseos I, § 1, p. 121 (GW II 29). 
thought from width and depth. ${ }^{35}$ On the contrary, in the Elements of Mathematics he considered lines, surfaces and solids to be extensive quantities: "a line is described when a point A moves to a point B"; a point is "what delimits itself wheresoever turned, or what does not have ends distinct from itself". ${ }^{36}$

In the earlier writings the impure nature of the definition relies mainly in the fact that geometry is considered as the science of space, and thus as having to do directly with physical things, of which it considers certain aspects (length, width, and height). ${ }^{37}$ In later writings, the definition is impure for a different reason: it relies on the notion of extension, which Wolff defines in the ontology as "multorum diversorum, aut, si mavis, extra se invicem existentium, coëxistentia in uno, atque conflituatur multorum extra se invicem existentium unione (the coexistence in one of several different, existing one outside the other, which is generated by their union)". ${ }^{38}$ A straight line is an extensive quantity because we can distinguish in it many separate parts that, once unified, generate the line. This notion of extension, which has been compared with the Aristotelian notion of continuity based on contiguity, ${ }^{39}$ is taken from philosophy rather than from physical applications, but again is not explained in geometrical terms. On the contrary, the insistence on the operation of unification of separate parts is clearly opposite to Newton's fluentist perspective: “Lines are described, and by describing are generated,

35 See Mathematisches Lexicon, p. 792 (GW I 11).

36 See Elementa Matheseos I, § 10, p. 122 and § 6, p. 121(GW II 29) respectively.

37 One should also note that geometry is not considered as a mixed or applied discipline, and not as a mixed science, as it will be often the case in the $19^{\text {th }}$ century. Wolff claims that geometry is pure rather than applied, because it concerns "the straight line in general", and not "the straight line as the width of a river, the height of a body, the distance between earth and moon", and so on. See Mathematisches Lexicon, pp. 866-7 (GW I 11).

38 See Philosophia prima sive Ontologia, Part II, Sect. I, Chap. II, § 548, p. 428 (GW II 3).

${ }^{39}$ See Antonio Moretto, La rilevanza matematica della discussione sui concetti di continuo e di funzione nella filosofia tedesca dell'età dell'illuminismo. Grandezza estensiva, continua e intensiva in Leibniz, Wolff, Baumgarten e Kant, in: Fenomenologia e società 18/2-3 (1995), p. 117. 
not by any apposition of Parts, but by a continual motion of Points". ${ }^{40}$ The shift from a physical to a philosophical definition of extension does not alter the opposition that Wolff introduces between geometry, and Leibniz's calculus situs, which is considered as an investigation of the respective position of lines (e.g. of orthogonality and parallelism) rather than of their length. ${ }^{41}$ The latter, as it was already the case for algebra and analysis, is considered as a calculus and is not really included in Wolff's definition of mathematics as the science of quantities.

So, Wolff does not seem to include qualities in the definition of geometry. Yet, in the Latin version of the Elements of Mathematics he aims at improving Euclid's order of geometrical propositions, and uses a philosophical notion of similarity to ground the geometrical similarity between angles and figures. Wolff shares Leibniz's conception of similarity, at least inasmuch it concerns the fact that "qualities are those properties of an object that can be distinctly known or understood when viewed in isolation from other objects, and the similarity of two objects consists in identity of such properties". ${ }^{42}$ So, on the one hand, similarity is not obtained by proportions, on the other hand it makes possible to investigate qualities as well as quantities in geometry. We find here another example of impurity underlined by Lambert and Kant: the use of a philosophical notion of similarity to exploit the geometrical notion of similarity, and to reform the logical order of the Elements. ${ }^{43}$

40 See Isaac Newton, Quadrature of curves, in: Mathematical Works of Isaac Newton, ed. by D.T. Whiteside, New York, vol. 1, 1964, p. 141.

41 See Mathematisches Lexicon, p. 292 (GW I 11).

42 See Daniel Sutherland, Philosophy, Geometry, and Logic in Leibniz, Wolff, and the Early Kant, op. cit., p. 166.

43 See Sutherland, Philosophy, Geometry, and Logic in Leibniz, Wolff, and the Early Kant, op. cit., p. 155. 


\subsection{Algebraic quantities}

We have already mentioned that algebra as a discipline is distinguished by Wolff both from the literal calculus as from Leibniz's general investigation on qualities. On the one hand, it is defined as the science that uses equations to solve given problems, thereby recalling its origin and development; on the other hand it is associated to the determination of the rules that govern the search for solutions, and to the application to infinitesimal small quantities. ${ }^{44}$ Yet, as Wolff distinguishes ancient from modern algebra, i.e. numerical [algebra numerosa] from literal equations [algebra speciosa], he defines the former as a calculus on numbers and the latter as a calculus on letters, thereby suggesting the close relationship between algebra and calculus. ${ }^{45}$

The notion of algebraic quantity is even more difficult to enucleate.$^{46}$ It is a quantity expressed in an algebraic way, an indeterminate number expressed through letters, ${ }^{47}$ whereas a quantity in general is something that can be increased or decreased. The choice of the terms 'vermehren' and 'vermindern', which derive from the terms 'mehr' und 'minus', i.e. from the names of the arithmetical signs + and -, already indicates the algebraic meaning attributed by Wolff to quantities, as well as his debt to Descartes:

\footnotetext{
${ }^{44}$ See Mathematisches Lexicon, p. 34 (GW I 11).

45 See Shabel, Mathematics in Kant's Critical Philosophy. Reflections on Mathematical Practice, op. cit.

46 In the entry "quantitas, eine Grösse" Wolff says that quantities, identified here with "indeterminate numbers" [undeterminierte Zahlen], are what can be increased or diminished [vermehren and vermindern\}, whereas in the entry "mathematics", defined as the science of quantities", the latter are defined as that which might be enlarged or reduced [vergrössern and verkleinern], without taking into due account the linguistic nuance between these respectively discrete and continuous terms. See Mathematisches Lexicon, p. 1143, and pp. 864-66 (GW I 11) respectively. Besides, Wolff uses the same term Grösse both to translate quantitas and to translate 'Moles, Volumen', i.e. the space that a body occupies according to its lenght, height, and width. See Mathematisches Lexicon, pp. 906-7 (GW I 11). Cf. Paola Cantù, Aristotle's prohibition rule on kind-crossing and the definition of mathematics as a science of quantities, in: Synthese, 174/2 (2008), pp. 225-235.

47 See Mathematisches Lexicon, p. 1144, and p. 1143 (GW I 11) respectively.
} 
"Notandum est deinde, nihil ad istam aequalitatem reduce posse, nisi quod recipit majus et minus, atque illud omne per magnitudinis vocabulum comprehendi (One has to note, moreover, that nothing can be reduced to such an equality except what admits of more and less, and that all this is covered by the term 'magnitude')". ${ }^{48}$ Quantities are indeterminate numbers when it is unsettled to which unit they should refer: the proportion used to define a number is thus incomplete. The importance of defining quantities as indeterminate numbers relies in the fact that it becomes possible to apply them to "all what has been demonstrated upon numbers". ${ }^{49}$ A similar notion is maintained in the Latin version of the Elements of Mathematics, where quantities are distinguished in determinate and indeterminate, according to the fact that they refer to a given unit or to a vague unit: so for example the quantity of the width of a river is an indeterminate quantity that is referred to a vague unit, because the number associated to it might vary according to the measurement unit that is assumed. ${ }^{50}$

Anyway, algebraic letters always stand for quantities. Wolff's definition does not include qualities among the possible objects of algebra. Wolff seems to have been more influenced by the Cartesian symbolism in the treatment of geometrical figures than by the Leibnizian definition of quantity, which is determined by the presence of something to be measured and of something that might play the role of a measurement unit. $^{51}$ Leibniz himself remarked a discrepancy between his own conception and

${ }^{48}$ René Descartes, Regule ad Directionem Ingenii. Rules for the Direction of the Natural Intelligence, ed. by G. Heffernan, Amsterdam and Atlanta, GA, 1998, pp. 180-181.

${ }^{49}$ See Mathematisches Lexicon, p. 1143 (GW I 11).

50 See Elementa Matheseos I, §§ 13-14, p. 24, (GW II 29).

51 See Gottfried W. Leibniz, Initia rerum mathematicarum metaphysica, in: Leibnizens mathematische Schriften, ed. by C.I. Gerhardt, volume 7, Halle, 1863, pp. 18-19. Engl. transl in Gottfried W. Leibniz, Philosophical Papers and Letters: A Selection, ed. by L.E. Loemker, Dordrecht, Boston, and London, 1975, p. 667. 
Wolff's presentation of it. ${ }^{52}$ We have already mentioned that Wolff acknowledges the importance of Leibniz's calculus situs, but does not modify the definition of geometry in order to include the study of orthogonality or parallelism. Again, he introduces a distinction between absolute, positive and privative quantities that had never been thematized before, ${ }^{53}$ but then restricts mathematics to positive quantities, claiming that positive and negative (privative) quantities are not homogeneous, i.e. once multiplied, cannot exceed one another.

The insistence on a condition of homogeneity was probably derived from Euclid's Elements, but might also be related to the fact that Wolff conceived proportions as a way to determine numbers rather than as a way to study qualitative relations between things. It is the definition of number as the fourth proportional that forced him to include among quantities only those that can be put in proportion, i.e. only homogeneous quantities. This was also the main reason why Wolff did not admit negative quantities: given that they lack some positive property (and should thus be rather called privative quantities), they cannot be compared to quantities that have positive properties. So, setting apart the critical remarks by mathematicians who saw a regressive trait in this aspect of Wolff's mathematics (see e.g. Kästner's criticism), ${ }^{54}$ Schubring has convincingly shown that Wolff was quite consistent on this point, and that his arguments were based on claims that had been advanced by Arnauld and accepted also by Leibniz. ${ }^{55}$ The same line of reasoning was used to defend the idea that infinitesimals could

52 Leibniz actually refers to an anonymous review of the first volume of the Elementa Matheseos published in the Acta Eruditorum in 1714. See Leibniz, Initia rerum mathematicarum metaphysica, op. cit. p. 17; Engl. transl. p. 667 and p. 673, fn. 1. See also De Risi, Geometry and Monadology, op. cit., p. 118.

53 See Schubring, Conflicts Between Generalization, Rigor, and Intuition, op. cit., p. 96.

54 Ibid., p. 134 and p. 135, fn. 77.

55 Arnauld refused to admit negative quantities on the basis of the following reasoning applied to the proportion $-1: 1=1:-1$ : How is it possible that a minor is to a major like a major to a minor? See Schubring, Conflicts Between Generalization, Rigor, and Intuition, op. cit., p. 97. 
be ignored, because they are not homogeneous to other quantities, and thus cannot enter in the proportion used to define numbers. ${ }^{56}$ So, if one accepts Wolff's definition of number, then it is difficult to include negative numbers. In this case, Wolffs' definitions do not account for a mathematical practice that he knew and accepted in applications, where he used numbers preceded by the sign minus to express debts. A reason for this discrepancy between conceptualization and practice might rely in the idea that the 'numbers' used in the calculus of debts and credits are not a true case of numbering, because it is not possible to build a proportion based on the similarity with quantities to be measured, which are, in a sense, always something, and thus positive.

Another line of criticism against Wolff's algebra concerns his 'regressive' insistence on geometrical representation. Yet, the latter is not merely the effect of the influence of Descartes' geometrical operations on segments, but also a consequence of the application of his mathematical method. Wolff's geometrical representation is coherent with his insistence on the nature of definitions that have an abstract as well as a constructive component. ${ }^{57}$ So, the impurity related to the use of a philosophical definition of similarity in geometry is associated to the impurity of reformulating the Elements giving preeminence to thirty practical problems, or practical constructions. ${ }^{58}$ Besides, the insistence on the geometrical representation had also some innovative aspects, because Wolff, influenced by Leibniz's calculus, explicitly defined the notion of a variable quantity [quantitatis variabilis] opposed to that of constant quantity. Variable quantities are quantities that always increase or decrease, when other quantities increase or decrease. What strikes the modern reader here is the constructive flavor of Wolff's

56 Ibid., pp. 239 ss.

57 As Shabel puts it, "geometrical constructions not only provide a representation of mathematical objects but also constitute their definition". See Shabel, Mathematics in Kant's Critical Philosophy. Reflections on Mathematical Practice, op. cit., p. 162.

58 See Sutherland, Philosophy, Geometry, and Logic in Leibniz, Wolff, and the Early Kant, op. cit., p. 163. 
approach. Yet, this aspect should not be overemphasized, because it is somehow derived from practical applications rather than from a theoretical reflection on the constructability of mathematical concepts.

\subsection{Probability theory}

It has often been claimed that Wolff did not take into due account the mathematical theory of probability, and especially its improvements by Jakob Bernoulli. ${ }^{59}$ On the contrary, Wolff was aware of the contemporary mathematical developments already in $1714 .^{60}$ Wolff developed an original theory of probability, that had a considerable influence on Kahle, Mendelssohn, Bolzano, and Kästner. ${ }^{61}$ In the light of the contemporary distinction between logical, subjective and objective probability, ${ }^{62}$ Wolff's notion

59 See Nicolao Merker, L'illuminismo Tedesco. Età di Lessing (1968), Germ. transl. by D. Doucet-Rosenstein and R. Wagenknecht in: Die Aufklärung in Deutschland, München 1982, p. 84; see Raffaele Ciafardone, Illuminismo tedesco. Metodo filosofico e premesse etico-teologiche (1690-1765), Rieti 1978, p. 82; see Schönfeld, Wolff, Christian (1679-1754), op. cit.

60 See for example the (anonymous) review to Bernoulli's Ars Conjectandi published in the Acta Eruditorum in 1714 (GW II 38.1), but also Wolff's references to the same book in the Mathematisches Lexicon (GW I 11, p. 401), and in the bibliographic section of Elementa Matheseos V, Part IV, $§ 14$, p. 57 (GW II 33). Wolff's definition of stochastic (Muthmassungskunst) as the art to determine the probability of a thing is an almost exact transcription of Bernoulli's definition of probability. See Mathematisches Lexicon pp. 1328-29 (ibid.) and Jakob Bernoulli, Ars Conjectandi. Basel, 1713, §IV.2, p. 213. See also Cataldi Madonna, Wahrscheinlichkeit und wahrscheinliches Wissen, op. cit.

61 See ibid., pp. 4-5; see Cataldi Madonna, Wolff, Bolzano e la probabilità, op. cit.; see Edith Dudley Sylla, Mendelssohn, Wolff, and Bernoulli on Probability, in: Moses Mendelssohn's Metaphysics and Aesthetics, ed. by R. Munk, Dordrecht, Heidelberg, London and New York, 2011, pp. 41-63; see Rüdiger Campe, The game of probability. Literature and calculation from Pascal to Kleist. Stanford, 2012, especially pp. 305-310 and p. 256.

62 I distinguish here three ways of conceiving probability: 1) a logical (objective) notion, that should measure the strength of the evidence for a given event, on the basis of the analysis of the space of possible outcomes; 2) a subjective notion, that should measure the degree of an agent's belief in his own assertions by an investigation of his betting behavior; 3) a scientific (objective) 
could be considered to be at the same time logical and subjective, because it is based on the space of all requisites for the truth of a proposition, and can measure the degree of belief of the agent. ${ }^{63}$

Wolff aims at developing Leibniz's logica probabilium, which is based on the principle of sufficient reason, in the light of the contemporary mathematical notion of probability developed among others by Jakob Bernoulli. Wolff defines the degree of probability of a proposition ${ }^{64}$ as the ratio between the number of requisites for the truth of the

notion that applies to the relations between things (either by considering all actual outcomes or by analyzing the physical propensity or disposition towards a given outcome). See Alan Hàjek, Interpretations of probability, in: The Stanford Encyclopedia of Philosophy, ed. by E. N. Zalta, Stanford, Winter 2012 Edition. Classical probability is usually associated to Laplaces' formulation, but it is related to the writings of several authors that were well known to Wolff (e.g. Pascal, Jakob Bernoulli, Huygens, and Leibniz). Even if its interpretation is multiple, it is often considered as an instance of a quasi-logical objective notion, because it is based on an exploration of the space of possibilities: the probability of an event depends on the ratio between the number of cases favorable to that event and the number of all possible cases. The subjective approach (De Finetti, Ramsey, Kemeny) connects probabilities with rational preferences and utilities, and finds its forerunners in Daniel Bernoulli. The third approach includes theories like frequentism, propensity, and the best system interpretations that were developed in late 19th or early 20th century: they are based on actual rather than on possible outcomes.

${ }^{63}$ Wolff was clearly aware of the distinction between objective and subjective probability, for he explicitly mentions Bernoulli's distinction between an objective treatment of certainty (concerning the actual existence, present or future, of a thing) and a subjective treatment of certainty (reltive to us and consisting in the measurement of our knowledge of that actuality). See Jakob Bernoulli, Ars Conjectandi, op. cit., § IV.1, p. 210 and Wolff's review, p. 22 (GW II 38.1).

${ }^{64}$ It should be noted that probability concerns propositions rather than inferences. The conclusion of an inference is probable only if one of the premises is probable, and not because the inference rule is probable. Wolff maintains, like Aristotle, that there is only one inferential structure (deduction), and that the probability concerns propositions. Claiming that there is a strong contuinity between Wolff's and Bolzano's notion of probablity, Cataldi Madonna insists on the fact that Wolff considers also the probability of implications-what he calls "quasi-implications"-but does not give textual support for this claim. See Cataldi Madonna, Wolff, Bolzano e la probabilità, op. cit., 
proposition that are accessible to an agent (insufficient reason), and the number of all requisites for the truth of that proposition (i.e. its sufficient reason). ${ }^{65}$ In other words, truth and falsity are the limit values 1 and 0 that such ratio might assume, when all requisites are known and the knowledge is certain.

This continuity between probable and certain knowledge explains why the theory of probability can be applied not only to the investigation of the physical world, but also to the solution of questions that belong to historical science, such as Süssmilch's population statistics. ${ }^{66}$ This change is made possible by the logical turn that is given to probability, which is no more considered as the probability of things (as it was the case in the mathematical textbooks), but rather as the probability of propositions, whereby the latter is grounded on the principle of sufficient reason, which is a general principal of all human knowledge. The requisites for the truth of a proposition are at the basis of both certain and uncertain knowledge: there is a difference of degree and not a difference of nature. ${ }^{67}$

p. 111. Wolff distinguishes demonstrations (demonstrationes), based on certain premises, from proofs (probationes) based on uncertain premises: proofs are probable if the premises are probable, and precarious if the premises are precarious. See Logica, §§ 599-602, pp. 446-447 (GW II 1.3). This does not imply, however, that Wolff admits probable inferences. On the contrary, the logical rules are the same both in demonstrations as in proofs, and this is exactly what allows him to establish a continuity between physico-mathematical sciences, and historical and social sciences.

65 See Philosophia rationalis sive Logica, §§ 579 (GW II 1.3). See also Cataldi Madonna, Wolff, Bolzano e la probabilità, p. 110.

66 Wolff wrote in the introduction to Süssmilch's book: “[A]s yet no one has discussed in a comprehensive theory how to use the faculties of reason in order to explore that which is probable. But attempts have been made to test how a theory of probability might be developed for the sake of use in everyday life. The present book is among these." See Campe, The game of probability, op. cit., pp. 216-217, 255-256, 448, fn. 1.

${ }^{67}$ On this application of the logic of probability both to physical sciences (the domain of the legiform) and the moral and historical sciences (the domain of singularities) see in particular Campe, The game of probability, op. cit., pp. 315-317. On the Leibnizian principle of sufficient reason 
Wolff's main contribution to the development of a an extended understanding of scientific knowledge concerns the attention to observations and experience as elements that might furnish a probable knowledge ${ }^{68}$ that is not opposed to the knowledge of truth, but rather presented in continuity with the latter. This continuity is guaranteed by Wolff's idea that, even if there are differences between mathematical, philosophical, and historical knowledge, there is somehow a unique methodology that unifies them, and that is based on the ideal of demonstrative knowledge. Wolff's treatment of probable reasoning (as depending on an insufficient knowledge of the requisites for the truth of the premises) better explains the role assigned to definitions in the mathematical method (see § 3.2), and the sense in which their incompleteness might produce a fallacy. ${ }^{69}$

\section{On Wolff's mathematical method}

\subsection{Many names, one method?}

It is questionable what should be understood as Wolff's mathematical method, first of all because Wolff calls his method by many different names: mathematical, geometrical, demonstrative, philosophical, scientific. ${ }^{70}$ Secondly, because it is defined in different ways in different texts; so, it is not clear in which discipline one should look for it: logic, where its principles and rules are clarified; philosophy, where it is applied in metaphysics; or mathematics, where it occurs in arithmetic, geometry, and algebra,

as common ground of true and probable knowledge, see also Cataldi Madonna, Wolff, Bolzano e la probabilità, op. cit., p. 116 ss.

68 See Cataldi Madonna, Wahrscheinlichkeit und wahrscheinliches Wissen, op. cit.; see also Zingari, Die Philosophie von Leibniz und die "deutsche Logik" von Christian Wolff, op. cit.

${ }^{69}$ See Philosophia rationalis sive logica II, Part II, Sec. 1, § 633, p. 461 (GW II 1.2). See Jean École, Introduction, in: Philosophia rationalis sive logica, pp. v-lxxxvii (GW II 1.1), and also Jean École, Introduction, in: Philosophia rationalis sive logica, esp. p. cv (GW II 1.2 ).

${ }^{70}$ See Tore Frängsmyr, Christian Wolff's mathematical method and its impact on the Eighteenth century, in: Journal of the History of Ideas, 36/4 (1975), p. 655. 
but also in applications. Most studies in the literature focus on logic, philosophy, and the origins, rather than the achievements of Wolff's method. ${ }^{71}$ For example, it has been questioned whether Wolff's mathematical method is a heritage of Aristotle's syllogistic logic, of Scholastics, of Port Royal Logic, of the mathesis universalis tradition, of Euclid's Elements, of Newton, of Descartes and Tschirnhaus, of Barrow, or of Leibniz. ${ }^{72}$ In the following I will try to combine the two approaches, discussing the characterization of the method offered in the mathematical textbooks as well as its application in the definition of mathematical key concepts. Having analysed Wolff's main concepts in the former section, I will now discuss the features of the mathematical method and make references to several features of those definitions.

\subsection{Mathematical method as order}

Wollf's mathematical method concerns the order of exposition used by mathematicians: first, the definitions, then the axioms and postulates (or experiments and observations in mixed mathematics), and finally the theorems and problems, all accompa-

71 See in particular the literature mentioned in footnote 8. Paola Basso regrets that Wolff's method gets rid of the strictly geometrical nature, thus losing attention to the logic of discovery, to the investigation of the connection between truths, and to the limits of its application. Basso claims that the method thus becomes a universal and thus void method, whereby the order of exposition is much more important than the discovery of truths, and the effort to define is prior to the effort to prove. See Paola Basso, Il secolo geometrico, op. cit.

72 Cf. in particular Frängsmyr, Christian Wolff's mathematical method, op. cit., p. 656. Shabel, Mathematics in Kant's Critical Philosophy. Reflections on Mathematical Practice, op. cit.; cf. Dunlop, Mathematical method, op. cit.; cf. Vleeschauwer, La genèse de la méthode mathématique de Wolff op. cit.; cf. Zingari, Die Philosophie von Leibniz, op. cit. Significant exceptions are Sutherland, Schubring, Dauben and Scriba, who tend to focus on specific results of Wolff's mathematics, but do not connect them to the question of the method. See Sutherland, Philosophy, Geometry, and Logic in Leibniz, Wolff, and the Early Kant, op. cit.; see Schubring, Conflicts Between Generalization, Rigor, and Intuition, op. cit.; see Dauben, and Scriba, Writing the History of Mathematics. Its Historical Development, op. cit. 
nied by corollaries and scholia, whenever necessary. Definitions are the fundamental notions from which all the rest is deduced. ${ }^{73}$ The mathematical order thus focuses on definitions, and on the derivation of theorems and problems, as well as of axioms and postulates from them. If the derivation of theorems is a standard requirement of the axiomatic method from Euclid's elements onwards, the sense in which geometrical axioms could be derived from definitions needs to be clarified. This approach seems quite incompatible with modern axiomatics, where on the contrary, definitions do not play any inferential role, but rather serve as clarifications, whereas the axioms are the beginning of the inferential process. When Wolff aims at reforming Euclid in order to determine the "fundamental concepts from which all knowledge can be derived by means of definitions", ${ }^{74}$ he believes in a unique hierarchy of concepts, integrating geometry, philosophy, and all other branches of human knowledge. And he believes in the possibility of a conceptual analysis that enucleates the notions that should be taken as primitive: e.g. similarity is more fundamental than congruence in geometry, and thereby all theorems that depend on a principle of similarity should precede the theorems that depend on congruence. Wolff's concern for the right order of concepts is thus not completely opposed to foundational questions such as those that arose in Hilbert's Grundlagen, as he grouped theorems concerning basic relations such as incidence, order, congruence, parallelism and continuity. Besides, even in the $20^{\text {th }}$ century authors like Peano and Gödel, who had been strongly influenced by Leibniz, were quite responsive to the question of the right order of concepts. ${ }^{75}$

73 See Elementa Matheseos I, § 1-3, p. 5 (GW II 29).

74 See Sutherland, Philosophy, Geometry, and Logic in Leibniz, Wolff, and the Early Kant, op. cit., p. 168.

75 See Paola Cantù, The right order of concepts: Grassmann, peano, Gödel and the inheritance of Leibniz's universal characteristic, in: Philosophia Scientiae. Studies in History and Philosophy of Science, 18/1 (2014), pp. 157-182. 


\subsection{Mathematical definitions}

This idea of an integrated human knowledge explains Wolff's characterization of mathematical definitions as a special case of definitions in general. Definitions are fundamental notions of something, fundamental representations of a thing in the mind. ${ }^{76}$ Following Leibniz, Wolff distinguishes

1. clear (obscure) notions i.e. notions that are sufficient (insufficient) for one to recognize the denoted object whenever presented with it;

2. distinct (confused) notions, i.e. such that one can enumerate the characteristics [Merkmale] that make the recognition possible;

3. adequate [vollständig] (inadequate) notions, whenever the representation of the characteristics that make the recognition possible is itself distinct. ${ }^{77}$

Mathematical definitions should amount to distinct, and-whenever possibleadequate notions. Impure definitions that involve some features derived from applications might help us forming clear notions of mathematical objects, whereas philosophical notions might improve the distinctness and adequateness of the definitions. Even if Wolff does not say this explicitly, one might find a reason for admitting impure definitions in the search for virtues, such as clarity, distinctness and adequateness.

Wolff then considers two kinds of definitions:

1. nominal definitions are enumerations of the features that are sufficient to distinguish the represented thing (e.g. a square defined as a quadrilateral, equilateral and rectangular figure);

${ }^{76}$ See Elementa Matheseos I, § 3, p. 6 (GW II 29); see also Auszug aus den Anfangs-Gründen aller mathematischen Wissenschaften, § 2, p. 3 (GW I 25).

77 See Elementa Matheseos I, §§ 4-12, pp. 6-7 (GWII29). Cf. also Deutsche Logik, chap. I, § 9 ff., p. 126 ff. (GW I 1). 
2. real definitions are distinct notions that express the genesis of the thing, i.e. the way it might become (e.g. a circle conceived as described by the movement of a rectilinear line around a fixed point). ${ }^{78}$

The search for real definitions explains the importance given to geometrical constructions, and also the effort to separate each definition in two parts: a nominal and a real one. This holds for the definition of geometrical figures as extensive quantities (i.e. based on relations of contiguity between their parts), or as the result of specific geometrical constructions. But this might also explain Wolff's hesitation between physical definitions and geometrical definitions (e.g. infinitesimals are sometimes described as particles, straight lines as the length of physical things, and so on).

\subsection{The inferential role of definitions}

Wolff's effort to consider definitions not only as a "nomenclature teaching the names of things", but also as something from which we can derive postulates, had some undesirable consequences in mathematics. Lambert regretted that Wolff "granted too much to definitions", as he claimed that even the principles had to be preceded by definitions in order to be rightly conceived and understood. Lambert claimed that Wolff's use of philosophical definitions as nominal definitions that were assumed to wrongly prove certain theorems, had the effect that "the very proposition that every definition, before it is proven, is an empty hypothesis - the very proposition that Euclid knew so well and took so seriously-was, if not completely lost, then pretty much forgotten". ${ }^{79}$ Interestingly enough, Bolzano's own reformulation of Euclid's geometry was

78 See Elementa Matheseos I, §§ 13-18, p. 7 (GWII29).

${ }^{79}$ See J.H. Lambert, Theorie der Parallellinien, in: Die Theorie der Parallellinien von Euklid bis auf Gauss, ed. by Engel and Stackel, Leipzig, 1895, pp. 157-58, Engl. transl. by A. Laywine in: Kant and Lambert on geometrical postulates in the reform of metaphysics, in: Discourse on a New Method: Reinvigorating the Marriage of History and Philosophy of Science, ed. by M. Friedman, M. Domski, and M. Dickson, Chicago and La Salle, Illinois, 2010, p. 118. See also Jeremy Heis, Kant (vs. Leibniz, 
influenced by Wolff's principle of similarity, but Bolzano specifically mentions the influence he received from the formulation presented in the Ontology and only generically mention the treatment of similarity in mathematical writings. ${ }^{80}$ The comparison with Bolzano is interesting, because Bolzano, like Wolff, was a non-professional mathematician who published mathematical essays. Bolzano also used conceptual analysis as an inferential tool, obtaining results that are mathematically more interesting, as an inductive procedure to prove certain numerical equalities.

Wolff's understanding of definitions is entirely centered on Leibniz's idea of conceptual analysis and on the decomposition of a concept in its features. The main problem concerns the possibility of deriving relational properties of the denoted things from nonrelational features of the notions that compose their concept and that occur in Wolff's definition. Lambert would say that only postulates contain the mutual relation between concept and thing, because they concern the possibility of the construction of the thing and at the same time the universality of its concept, for it can be applied to any construction.

\section{$4 \quad$ Summary}

Wolff's mathematics is better known as the critical target of Gauss, Schumacher, Leibniz, Bernoulli, Kästner, Cantor, and other mathematicians, who disliked the fact that his books were conceived as textbooks rather than as research writings, and criticized some of his definitions. This criticism, as well as other remarks on mistakes made in Wolff's inferential procedures, prove how Wolff's philosophy and theory of knowledge influenced his mathematical orientation. But it is important to show that there is at

Wolff and Lambert) on real definitions in geometry, in: Canadian Journal of Philosophy, 44/5-6 (2014), pp. 605-630.

80 See Bernard Bolzano, Betrachtungen über einige Gegenstände der Elementargeometrie, Prag, 1804, Engl. transl. in The mathematical works of Bernard Bolzano, ed. by S. Russ, Oxford 2004, p. 42. 
least an internal coherence between the normative requirements suggested by Wolff's philosophy, and in particular by his conception of the mathematical method, and the notions he actually defined in his textbooks. The impurity of definitions and the impurity of proofs that has been charged against Wolff by Kant and Lambert was a trait that Wolff shared with other authors of his time such as Leibniz. Indeed, it constituted the fundamental desideratum of Wolff's own epistemology, because he believed in the integration of mathematical knowledge into the larger body of human knowledge, and shared the idea that a right order of concepts should not only be introduced separately in each discipline, but also in the general hierarchy of concepts. This holistic and at the same time hierarchic vision of human knowledge is certainly very far from successive hyper-specialization and separation of disciplines, but is part of a coherent epistemological frame. This explains why several topics that Wolff did not fully develop in his mathematical books (such as probability, and partly the theory of extensive quantities) are rather discussed in logic or in metaphysics. This confirms the thesis that Wolff's works (like Leibniz's, Newton's or Descartes') cannot be read separately, and that a fully complete view of Wolff's mathematics cannot be achieved without a deeper investigation of the relations between mathematics, ontology, metaphysics, and logic.

The analysis of Wolff's definitions of number and quantity in the light of his theory of what mathematical definitions should be, reveals on the one hand that Wolff's debt to Descartes-whose intense reading has been attested by Hofmann ${ }^{81}$-is perhaps as conspicuous as the influence he received by Leibniz, notwithstanding his defense of Leibniz in the priority controversy on the discovery of the infinitesimal calculus, and his acknowledgement of Leibniz highest contributions to algebra, universal mathesis and calculus situs. Besides, it reveals that Wolff's geometrical definitions were strongly influenced by Euclid-especially by Barrow's English edition of the Elements-as well

${ }^{81}$ See J.E. Hofmann, Vorwort to Mathematisches Lexicon, p. ix (GW I 11). 
as by Aristotle's notion of contiguity, rather than by Newton's fluentist conception of geometrical quantities.

\section{$5 \quad$ Reading notes}

Anonymous, Review of Bernoulli's Ars Conjectandi, in: Acta Eruditorum, 1714 (GW II 38.1)

Arana, Andrew, On formally measuring and eliminating extraneous notions in proofs, in: Philosophia Mathematica 17/2 (2009), pp. 189-207.

Arana, Andrew, Purity in arithmetic. Some formal and informal issues, in: M. Detlefsen and G. Link editors, Formalism and Beyond. On the Nature of Mathematical Discourse, Boston, 2014, pp. 275-314.

Aristotle, Posterior Analytics, 75a-75b, transl. by Jonathan Barnes, Oxford, 1994.

Basso, Paola, Il secolo geometrico. La questione del metodo matematico in filosofia da Spinoza a Kant. Firenze, 2004.

Bernoulli, Jakob, Ars Conjectandi, Basel, 1713.

Bolzano, Bernard, Betrachtungen über einige Gegenstände der Elementargeometrie, Prag, 1804. Engl. transl. in S. Russ editor, The mathematical works of Bernard Bolzano, Oxford 2004, pp. 25-82.

Bos, Henk J. M., Lectures in the History of Mathematics, London and Providence, 1993.

Calinger, Ronald S., Leonhard Euler: Mathematical Genius in the Enlightenment, Princeton, NJ, 2015.

Campe, Rüdiger, The game of probability. Literature and calculation from Pascal to Kleist. Stanford, 2012.

Cantor, Moritz, Vorlesungen über die Geschichte der Mathematik, vol. 3, Leipzig, 1898. 
Cantù, Paola, Aristotle's prohibition rule on kind-crossing and the definition of mathematics as a science of quantities, in: Synthese 174/2 (2008), pp. 225-235.

Cantù, Paola, The right order of concepts: Grassmann, Peano, Gödel and the inheritance of Leibniz's universal characteristic, in: Philosophia Scientiae. Studies in History and Philosophy of Science 18/1 (2014), pp. 157-182.

Cataldi Madonna, Luigi, Wahrscheinlichkeit und wahrscheinliches Wissen in der Philosophie von Christian Wolff, in: Studia leibnitiana 19/1 (1987), pp. 2-40.

Cataldi Madonna, Luigi, Wolff, Bolzano e la probabilità, in: S. Carboncini and L. Cataldi Madonna editors, Nuovi studi sul pensiero di Christian Wolff, Hildesheim and New York, NY, 1992, pp. 107-130.

Ciafardone, Raffaele, Illuminismo tedesco. Metodo filosofico e premesse eticoteologiche (1690-1765), Rieti, 1978.

Corr, Charles A., Christian Wolff and Leibniz, in: Journal of the History of Ideas, 36/2 (1975), pp. 241-262.

Dauben, Joseph W. and Scriba, Cristoph J., Writing the History of Mathematics. Its Historical Development, Basel, 2002.

De Risi, Vincenzo, Geometry and Monadology: Leibniz's Analysis Situs and Philosophy of Space, Basel, Boston and Berlin, 2007.

De Vleeschauwer, Herman J., La genèse de la méthode mathématique de Wolff, in: Revue belge de philologie et d'histoire 11 (1931), pp. 651-677.

Descartes, René, Regule ad Directionem Ingenii. Rules for the Direction of the Natural Intelligence, Engl. transl. by G. Heffernan, Amsterdam and Atlanta, GA, 1998.

Dudley Sylla, Edith, Mendelssohn, Wolff, and Bernoulli on Probability, in: R. Munk editor, Moses Mendelssohn's Metaphysics and Aesthetics, Dordrecht, Heidelberg, London and New York, 2011, pp. 41-63. 
Dunlop, Katherine, Mathematical method and Newtonian science in the philosophy of Christian Wolff, in: Studies in History and Philosophy of Science Part A 44/3 (2013), pp. 457-469.

École, Jean, Introduction, in: Philosophia rationalis sive logica I, pp. v-lxxxvii (GW II 1.1).

École, Jean, Introduction, in: Philosophia rationalis sive logica II, pp. v-ccxxxiii (GW II 1.2).

Frängsmyr, Tore, Christian Wolff's mathematical method and its impact on the eighteenth century, in: Journal of the History of Ideas 36/4 (1975), pp. 653-668.

Gauss, Christian Friedrich, Briefwechsel zwischen C.F. Gauss und H.C. Schumacher, ed. by C.A.F. Peters, vol. 4, Altona, 1862.

Hàjek, Alan, Interpretations of probability, in: E.N. Zalta editor, The Stanford Encyclopedia of Philosophy, Stanford, Winter 2012 Edition.

Heis, Jeremy, Kant (vs. Leibniz, Wolff and Lambert) on real definitions in geometry, in: Canadian Journal of Philosophy 44/5-6 (2014), pp. 605-630.

Hofmann, J.E., Vorwort to Elementa Matheseos I, pp. v-ix (GW II 29).

Hofmann, J.E., Vorwort to Mathematisches Lexicon, pp. v-xvi (GW I 11).

Hube, Johann Michael, Versuch einer Analytischen Abhandlung von den Kegelschnitten, Göttingen, 1759.

Lambert, Johann Heinrich, Theorie der Parallellinien, in: P. Stäckel and F. Engel editors, Die Theorie der Parallellinien von Euklid bis auf Gauss, Leipzig, 1895, pp. 157-58.

Laywine, Alison, Kant and Lambert on geometrical postulates in the reform of metaphysics, in: M. Friedman, M. Domski, and M. Dickson editors, Discourse on a New Method: Reinvigorating the Marriage of History and Philosophy of Science, Chicago and La Salle, Illinois, 2010, pp. 113-134.

Leibniz, Gottfried Wilhelm, Initia rerum mathematicarum metaphysica, in: C.I. Gerhardt editor, Leibnizens mathematische Schriften, vol. 7, Halle, 1863, pp. 18-19. Engl. 
transl in G.W. Leibniz, Philosophical Papers and Letters: A Selection, ed. by L.E. Loemker, Dordrecht, Boston, and London, 1975, pp. 666-674.

Leibniz, Gottfried Wilhelm, Mathesis universalis, in: C.I. Gerhardt editor, Leibnizens mathematische Schriften, vol. 7, Halle, 1863, pp. 49-76.

Marcolungo, Ferdinando L., Wolff e il problema del metodo, in: S. Carboncini and L. Cataldi Madonna editors, Nuovi studi sul pensiero di Christian Wolff, Hildesheim and Zürich and New York, 1992, pp. 11-37.

McRobert, Jennifer, Kant on negative quantities, real opposition and inertia, Paper Presented at the 2004 Meeting of the Western Canadian Philosophical Association in Victoria B.C., Canada, 2004.

Merker, Nicolao, L'illuminismo Tedesco. Età di Lessing (1968), in: Die Aufklärung in Deutschland, transl. by D. Doucet-Rosenstein and R. Wagenknecht, München 1982.

Moretto, Antonio, La rilevanza matematica della discussione sui concetti di continuo e di funzione nella filosofia tedesca dell'età dell'illuminismo. Grandezza estensiva, continua e intensiva in Leibniz, Wolff, Baumgarten e Kant, in: Fenomenologia e società 18/2-3 (1995), pp. 109-153.

Newton, Isaac, Quadrature of curves, in: Derek T. Whiteside (editor), Mathematical Works of Isaac Newton, vol. 1, New York, 1964, pp. 141-160.

Padoa, Alessandro, Che cosa è una relazione?, in: Atti della Accademia Reale delle Scienze di Torino, 41 (1905-06), pp. 818-826.

Padoa, Alessandro, Frazioni, relazioni ed astrazioni, in: Periodico di Matematica, (3) 25/7 (1910), pp. 257-258.

Peckhaus, Volker, Logik, Mathesis universalis und allgemeine Wissenschaft. Leibniz und die Wiederentdeckung der formalen Logik im 19. Jahrhundert. Berlin, 1997. 
Schönfeld, Martin, Wolff, Christian (1679-1754), in: D.M. Borchert, editor, Encyclopedia of Philosophy, vol. 9, Detroit, 2006, pp. 822-832.

Schubring, Gert, Conflicts Between Generalization, Rigor, and Intuition. Number Concepts Underlying the Development of Analysis in 17th-19th Century, New York, NY, 2005.

Shabel, Lisa, Mathematics in Kant's Critical Philosophy. Reflections on Mathematical Practice, New York and London, 2002.

Sutherland, Daniel, Philosophy, Geometry, and Logic in Leibniz, Wolff, and the Early Kant, in: M. Friedman, M. Domski, and M. Dickson, editors, Discourse on a New Method. Reinvigorating the Marriage of History and Philosophy of Science, Chicago, 2010, pp. 155--192.

Tonelli, Giorgio, Der Streit über die mathematische Methode in der Philosophie in der ersten Hälfte des 18. Jahrhunderts und die Entstehung von Kants Schrift über die "Deutlichkeit”, in: Archiv für Philosophie 9 (1959), pp. 51-84.

Walton, Craig, Ramus and Socrates, in: Proceedings of the American Philosophical Society $114 / 2(1970)$.

Zenker, Kay, Vorwort to Auszug aus den Anfangs-Gründen aller Mathematischen Wissenschaften, pp. 5--24 (GW I 25).

Zingari, Guido, Die Philosophie von Leibniz und die "deutsche Logik" von Christian Wolff, in: Studia Leibnitiana 12/2 (1980), pp. 265-278. 